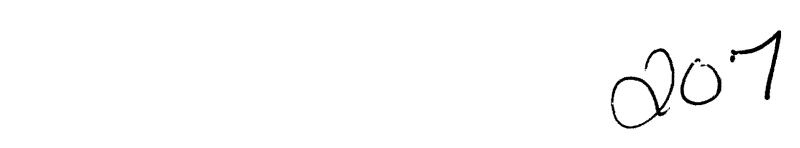

Reprinted from Annals of Surgery, Vol. 172, No. 1, July 1970

Copyright (1) 1970 by J. B. Lippincott Company

Printed in U. S. A.

\title{
Urological Complications in 216 Human Recipients of Renal Transplants
}

\author{
T. E. Starzl, M.D., Ph.D., C. G. Groth, M.D., C. W. Putnam, M.D., \\ I. Penn, M.D., C. G. Halgrimson, M.D., A. Flatmark, M.D., \\ L. Gecelter, M.D., L. Brettschneider, M.D., O. G. Stonington, M.D. \\ From the Department of Surgery and the Division of Urology, University of \\ Colorado School of Medicine and Veterans Administration Hospital, \\ Denver, Colorado
}

For the most part, the surgical technics of kidney transplantation have been standardized. ${ }^{3,8,10,11,17,25}$ The least satisfactory aspect of this operation is provision of urinary drainage as will be demonstrated by an analysis of the urologic complications encountered in 216 consecutive recipients of renal grafts at the Colorado General and Denver Veterans Administration Hospitals.

The Denver series is a useful one with which to study the attributes and deficiencies of urinary drainage procedures, not only because of the large numbers of patients, but also because all operations reported were performed at least one year ago, thereby assuring reasonably long fol-

Submitted for publication September 8, 1969.

This work was supported by United States Public Health Service grants AM-12148, AI-AM08898, AM-06344, AM-07772, AI-04152, FR-00051 and FR-00069. low-up. Furthermore, it has been possible to compare the alternative methods of ureteroneocystostomy and ureteroureterostomy, since a large number of reconstructions were performed with each method. Finally, considerable information was acquired on treatment of early and late complications which followed either type of ureteral reconstruction.

\section{Case Material}

Two hundred sixteen patients, aged 3 to 57 years, had renal transplantations from 1 to $7 \frac{1}{2}$ years ago. A number of the recipients received more than one kidney so that the total number of homografts used was 234 . One hundred seventy-two of these organs were obtained from family members (including three identical twins). The other 62 were either from cadaveric donors or non-related volunteers. Since the source of 


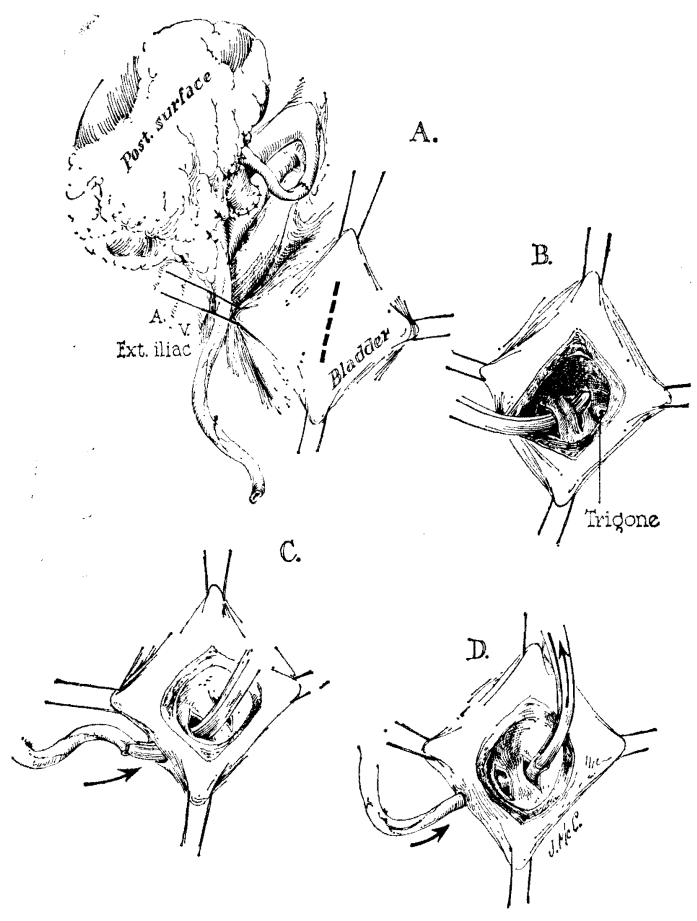

FIG. 1. Ureteroneocystostomy: A. The incision in the dome of the bladder is usually no more than $1.5 \mathrm{~cm}$. B. Development of the submucosal tunnel. Often the more lateral counterincision is not necessary. C, D. Placement of the ureter within the tunnel. The passage through the muscular layers should be widely dilated.

the kidney did not influence the incidence or type of urologic complications to a statistically significant degree, the distinction of donor source will not be discussed further.

In presenting the results of urinary tract reconstruction, all statistics will be based upon the relation of complications to the total number of transplantations. However, a note may also be in order concerning the fate of the patients. One hundred fifty-five of the recipients $(71.6 \%)$ survived at least 1 year. Between 12 months and the sixth post-transplantation year, 23 of these 155 patients died leaving a population of 132 $(61 \%)$ which is being studied after one to $71 / 2$ years. Thirty-three living patients with the longest follow-up have survived from $5 \frac{1}{2}$ to $7 \frac{1}{2}$ years postoperatively.
The general technics of immunosuppression used in all but identical twins have been described elsewhere, ${ }^{25}$ and included azathioprine, prednisone, actinomycin $\mathrm{C}$ and local homograft irradiation. In addition, the last 101 patients received adjuvant therapy with heterologous antihuman-lymphocyte globulin (ALG) prepared from the serum of immunized horses. ${ }^{28}$

Urine cultures for aerobic and anaerobic bacteria were obtained two or three times a week during hospitalization and once a week or less frequently after discharge. If these were positive, specific antibiotic therapy was administered which was based upon sensitivity determinations. In the results, data will not be given on the high incidence of bacteriuria ${ }^{22,25}$ in the early post-transplantation period which has consistently been 35 to $40 \%$. However, attention will be drawn to those patients who were left with chronic urinary tract infections.

Intravenous urograms were obtained during the first few postoperative weeks; these were repeated every 3 to 6 months. Double dose injection or infusion technics were used on occasion, and in a few cases cystourethrograms or retrograde pyelograms were necessary.

\section{Operative Procedures}

\section{Ureteroneocystostomy}

Urinary drainage of 178 of the 234 kidneys was established at the time of transplantation by ureteroneocystostomy. The technic used ${ }^{25}$ is summarized in Figures 1 and 2. The principles involved are formation of a capacious submucosal bladder tunnel for the ureter (Fig. 1) and the creation of a slightly everted hood with its tip (Fig. 2). The ureteral nipple is placed within a few millimeters of the natural ureteral orifice on that side, the most convenient location usually being just lateral and superior to the patient's own ureteral orifice. The utmost precaution should be 
taken not to injure the latter structure. If cystoscopy becomes necessary in the postoperative period, it is easy to visualize both the original and the new ureteral orifice if the ureteroneocystostomy has been placed in the recommended location.

A number of technical details are designed to insure against postoperative leakage of urine from either the cystotomy or the implantation site. An accurate mucosa to mucosa approximation at the ureteroneocystostomy is important (Fig. 2). Moreover, a small cystotomy is used (Fig. 1A). After completing the implantation, the cystotomy is closed in three layers using an inner row of continuous 4-0 chromic catgut through only the mucosa, a middle row of the same suture material through muscle, and an outer layer of interrupted 4-0 silk.

Special care is necessary to prevent postoperative hemorrhage from the implantation site. The homograft ureter tends to become progressively more hyperemic for a number of hours after transplantation. Consequently, failure to control small bleeding points in the ureteral tip may result in relatively major and progressive hemorrhage after the operation is finished.

The transplant wounds are not usually drained. Ureteral splints or catheters are avoided. A bladder catheter which is placed immediately before operation is ordinarily removed on the following morning to prevent the attendant bacterial contamination described by Hinman et al. ${ }^{7}$

\section{Ureteroureterostomy}

In 55 instances, the initial reconstruction of the urinary tract was with ureteroureterostomy. In most, this procedure was performed even though ureteroneocystostomy would have been feasible. However, in a minority, ureteroureterostomy was selected because the homograft ureter was too short to reach the bladder or because of other technical factors such as scarring of the bladder from previous operation. In almost all of these patients, bilateral nephrec-
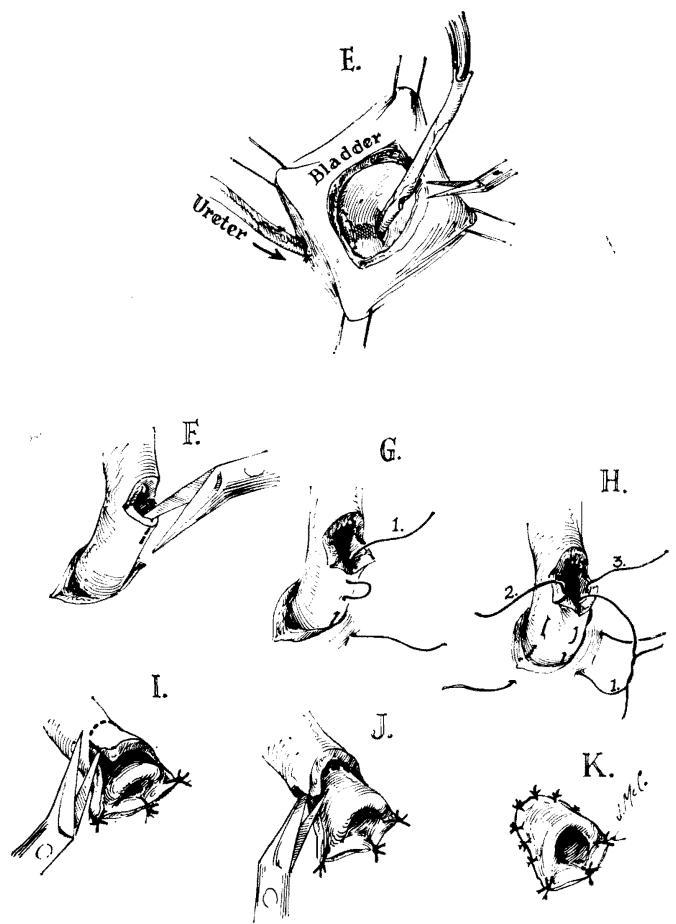

FIG. 2. Ureteroneocystostomy (cont.): Trimming of the ureter, formation of a flat nipple, and uretero-vesical anastomosis. The sutures are placed with 5-0 or 6-0 plain catgut on a swaged needle.

tomy and splenectomy were carried out through an upper midline incision (Fig. $3 \mathrm{~A}$ ) either on the day of transplantation or at some time previously; in the few exceptions only the host kidney on the side of the proposed transplant was excised. When the recipient's kidneys were removed, the ureters were tied just below the ureteropelvic junction (Fig. 3A), taking care to include only the ureter in these ligatures. It was then possible to deliver the remaining ureter into the ipsilateral iliac fossa (Fig. 3B) without a single instance of significant hemorrhage from the intervening retroperitoneal space.

The final mobilization of the portion of the recipient's own ureter to be used for anastomosis is usually not begun until the homograft has been revascularized in its extraperitoneal bed (Fig. 3C). At this time, the autologous ureter is freed by incising the filmy areolar layer that binds it to the 


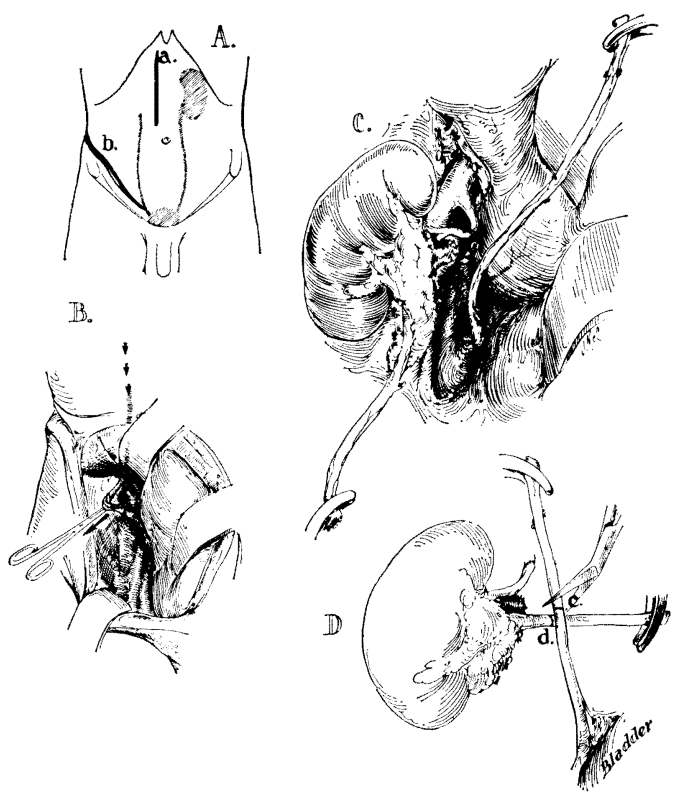

FIG. 3. Ureteroureterostomy: A. Incision for bilateral nephrectomy and splenectomy (a). The ureter is tied just below the ureteropelvic junction. The lower incision (b) is for kidney transplantation. B. Recipient site for transplantation, showing the recipient ureter being delivered into the iliac fossa by gentle traction. C, D. The vascular anastomoses have been completed. The donor and recipient ureters are positioned to be adjacent to each other and are tailored.

medially reflected retroperitoneal tissue. Great care is taken to protect the blood supply. One or more small twigs from the branches of the hypogastric artery can almost always be found passing to the posterior wall of the midpelvic ureter; these can usually be preserved.

The homograft and recipient ureters are then tailored to an appropriate length (Fig. 3D). These segments should be cut with some extra length since a redundant reconstructed ureter is preferable to one with tension on the anastomosis. The ureteral arteries of both segments are suture ligated with 6-0 silk near the site of the transections.

A single layer anastomosis is performed with 6-0 or 7-0 silk which is swaged on fine cardiovascular needles. Usually eight sutures are used. These pass through all layers of the wall except the mucosa (Fig.
$4 \mathrm{~A}$ and $\mathrm{B}$ ). It is convenient to start with two corner sutures and to use these in guiding the subsequent placement of others. For the back row, the ureter is turned (Fig. $4 \mathrm{C}$ ). If the anterior half of the anastomosis is examined at this time from within the lumen, it should not be possible to detect the previously placed silk. If intraluminal silk can be seen, the sutures were too deeply placed and should be removed.

The possibility of developing an acute urinary fistula is increased if through and through sutures are used, since fluid tends to leak out through the needle holes. However, if the technic is scrupulously followed, the intact mucosa serves as a waterseal (Fig. 4D). Ureteral splints or catheters are not used. The wounds are often drained. The bladder catheter is removed the morning after operation.

\section{Ureteropyelostomy}

This procedure was used initially in only one patient and for a special indication. After revascularizing the renal homograft,

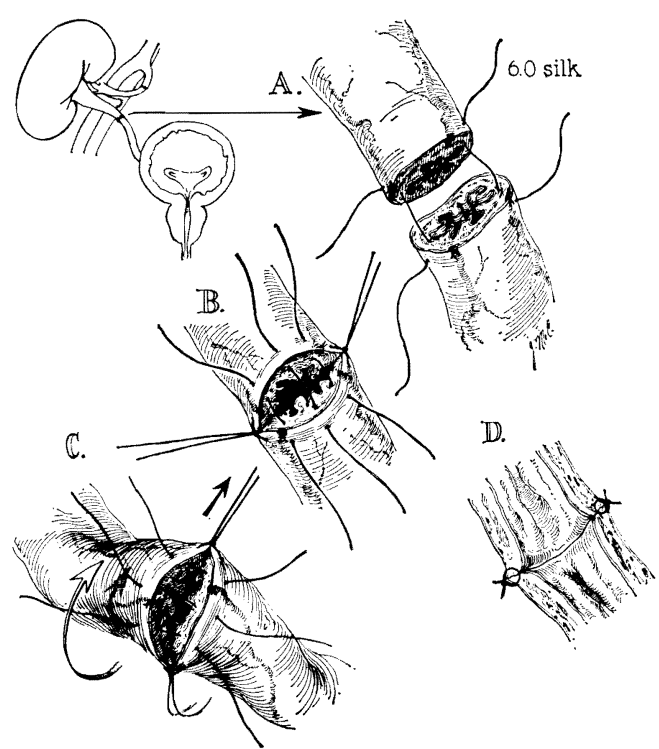

Fig. 4. Ureteroureterostomy (cont.): Single layer anastomosis performed with 6-0 or 7-0 silk swaged on fine cardiovascular needles. In $\mathrm{D}$ is shown a longitudinal section with correct placement of the silk sutures. Note the intact mucosa, with no sutures extending into the lumen. 

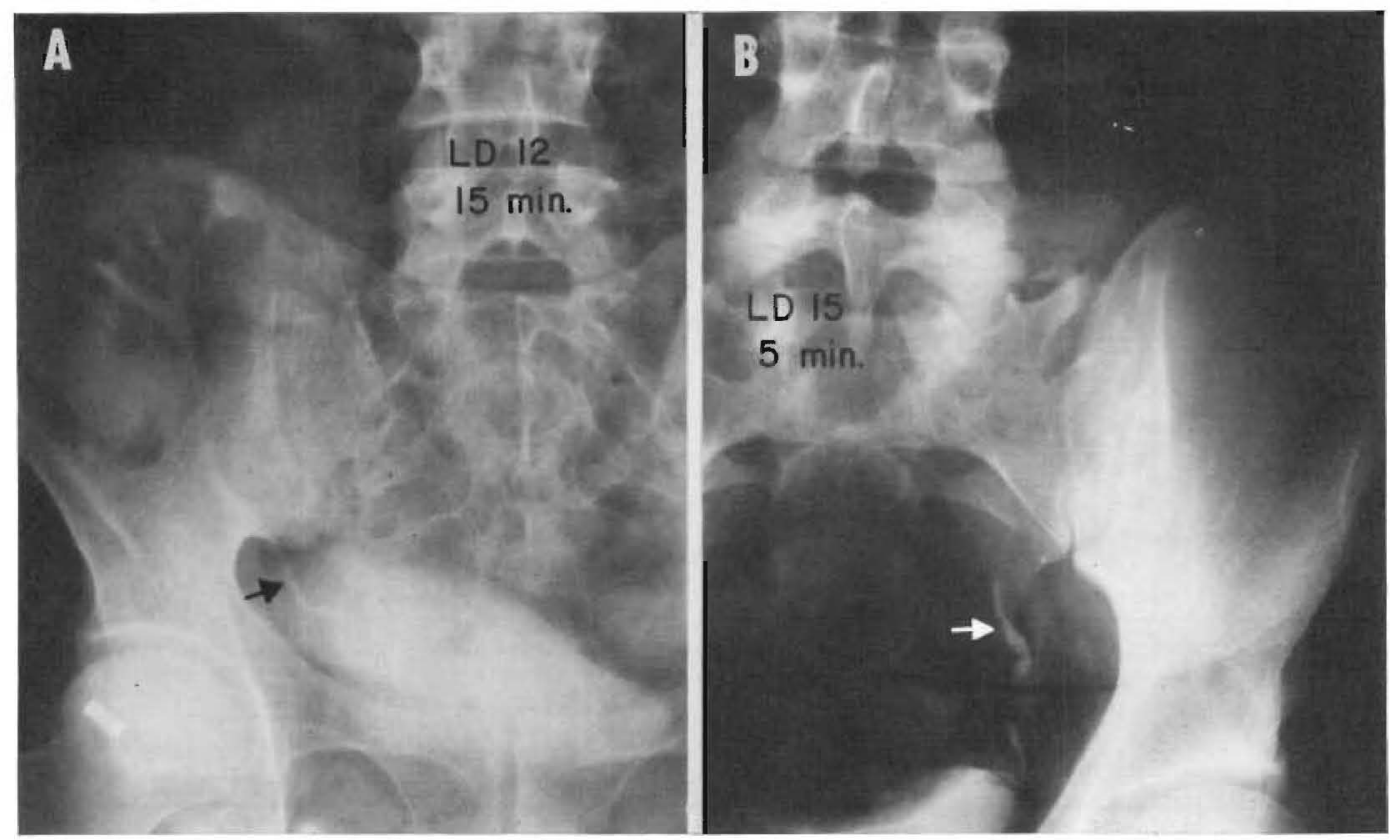

Fig. 5. Late intravenous urograms in patients whose urinary tracts were reconstructed satisfactorily with ureteroneocystostomy. A. Six years post-transplantation. The donor was a nontwin brother. Note the small caliber of the ureter (arrow). B. Six years and 2 months after transplantation from an older brother. Note the small size of the ureter (arrow).

bleeding from the cut end of the transplanted ureter was almost impossible to control. Eventually it was realized that this was due to venous hypertension which affected all of the ureter but not the pelvis. The recipient ureter was anastomosed endto-end to the narrow neck of the homograft pelvis using essentially the same technic as described above for ureteroureterostomy. There were no postoperative complications.

\section{Outcome of Primary Ureteroneo- cystostomy}

The majority of the 178 primary ureteroneocystostomies were satisfactory on both a short and long-term basis (Fig. 5). However, postoperative difficulties directly ascribable to the ureterovesical anastomosis were observed after $16(9.0 \%)$ of the transplantations. These proved to be far more life threatening if they evolved during the first $1 \frac{1}{2}$ months posttransplantation than if

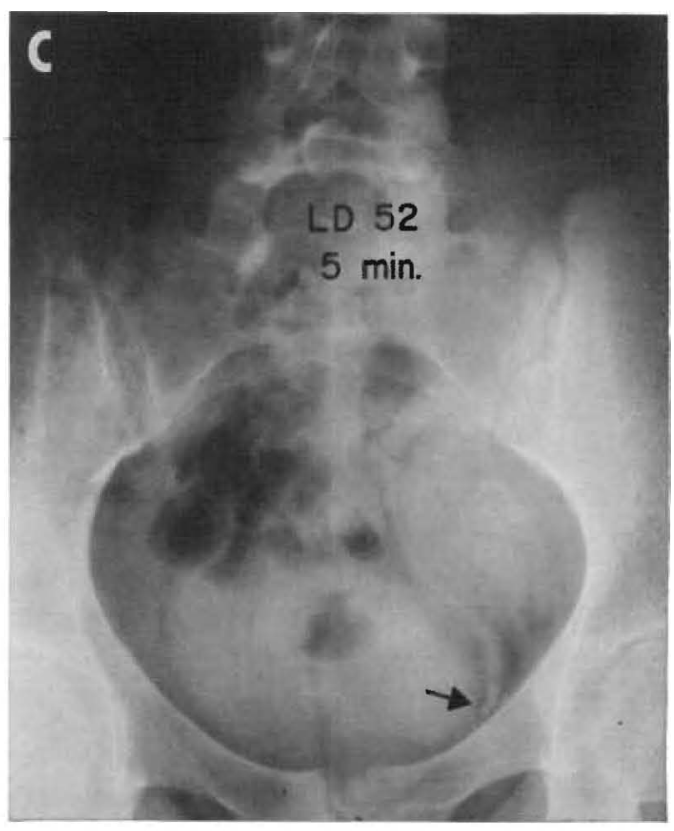

FIG. 5C. A paternal homograft 51/2 years after transplantation. The ureteroneocystostomy site is well seen (arrow). 


\begin{tabular}{|c|c|c|c|c|c|}
\hline Complication & No. & Treatment & & $\begin{array}{l}\text { Died before } \\
1 \text { Year }\end{array}$ & $\begin{array}{l}\text { Death Di- } \\
\text { rectly At- } \\
\text { tributable } \\
\text { to Com- } \\
\text { plication }\end{array}$ \\
\hline \multicolumn{6}{|c|}{ Primary Ureteroneocystostomy $(178)$} \\
\hline Early hemorrhage & 2 & Ureteroureterostomy & 2 & 2 & 1 \\
\hline Early urine fistula & 3 & $\begin{array}{l}\text { Reimplantation } \\
\text { Ureteroureterostomy } \\
\text { Nephrectomy }\end{array}$ & $\begin{array}{l}1 \\
1 \\
1\end{array}$ & $\begin{array}{l}1 \\
0 \\
1\end{array}$ & $\begin{array}{l}1 \\
0 \\
0\end{array}$ \\
\hline Early obstruction & 4 & $\begin{array}{l}\text { Reimplantation } \\
\text { Ureteropyelostomy } \\
\text { Ureteroureterostomy }\end{array}$ & $\begin{array}{l}1 \\
2 \\
1\end{array}$ & $\begin{array}{l}1 \\
0 \\
0\end{array}$ & $\begin{array}{l}1 \\
0 \\
0\end{array}$ \\
\hline Late stricture & 5 & $\begin{array}{l}\text { Ureteroureterostomy } \\
\text { Ureteropyelostomy }\end{array}$ & $\begin{array}{l}4 \\
1\end{array}$ & $\begin{array}{l}0 \\
0\end{array}$ & $\begin{array}{l}0 \\
0\end{array}$ \\
\hline Lymphocele & 2 & Drainage of lymphocele & 2 & 0 & 0 \\
\hline Total & $16 / 178(9.0 \%)$ & & & 5 & 3 \\
\hline \multicolumn{6}{|c|}{ Primary Ureteroureterostomy (55) or Ureteropyelostomy (1) } \\
\hline $\begin{array}{l}\text { Early urine fistula } \\
\text { Late calculus }\end{array}$ & $\begin{array}{l}6 \\
1\end{array}$ & $\begin{array}{l}\text { Ureteral reanastomosis } \\
\text { Ureteral reanastomosis }\end{array}$ & $\begin{array}{l}6 \\
1\end{array}$ & $\begin{array}{l}3 \\
0\end{array}$ & $\begin{array}{l}2 \\
0\end{array}$ \\
\hline Total & $7 / 56(12.5 \%)$ & & & 3 & 2 \\
\hline
\end{tabular}

* Early indicates that the complication was diagnosed during the first 6 weeks post-transplantation.

Late complications were $3 \frac{1}{2}$ months to $2 \frac{1}{2}$ years after transplantation.

they developed later. Consequently, the time interval of six weeks has been arbitrarily selected as the basis for the following classification of early and late complications (Table 1).

\section{Early Complications (First Six Weeks)}

There were a total of nine early complications $(5 \%)$ that necessitated reopening the transplant wound. The procedures carried out were nephrectomy (one example), revision of the ureteroneocystostomy (two examples), conversion to ureteroureterostomy (four examples), or conversion to ureteropyelostomy (two examples).

Hemorrhage. In two of the nine patients the indication for reintervention was hemorrhage. The ureter of one of these homografts had undergone a venous infarction causing massive bleeding both within and outside the bladder. The hemorrhage in the other case was arterial and originated from the ureteral tip.

Even with attempts at meticulous hemostasis most patients had some postoperative hematuria which usually cleared after 12 to 24 hours. However, in addition to the two patients who required reoperation, there were three more in whom hemorrhage was severe enough to require cystoscopy and transurethral cauterization of a bleeding point at the ureteral tip.

Urinary Fistula. The three fistulas $(1.7 \%)$ had different etiologies. One, which was diagnosed at 4 days, was apparently due to a defect left in the ureterovesical anastomosis. The second occurred 8 days posttransplantation when the distal inch of the ureter became necrotic. In the third, a necrotic pelvis was found at reoperation 19 days after homotransplantation, and the 

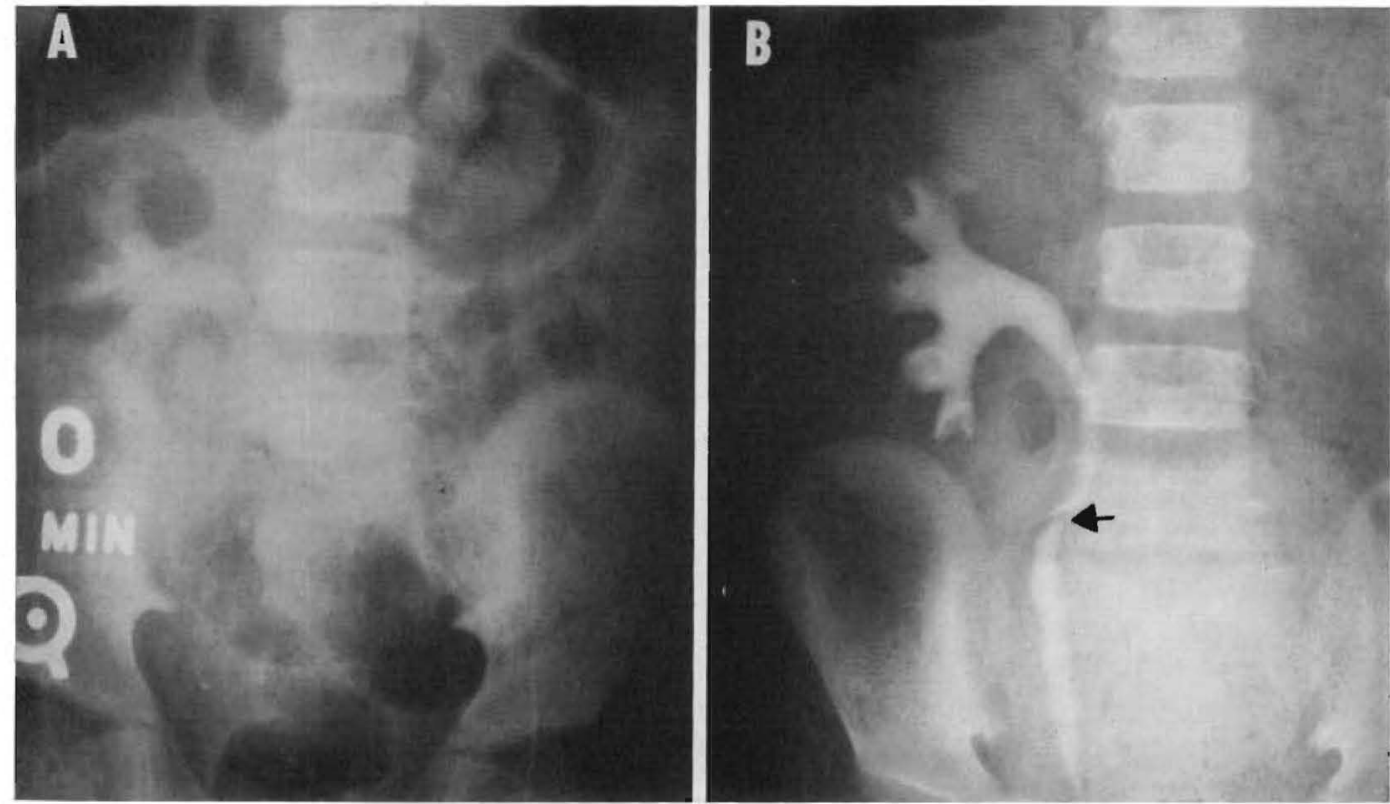

FIG. 6. Intravenous urograms in an 11 -year-old child whose first urinary tract reconstruction was with ureteroneocystostomy. The kidney was from a cadaveric donor. A. Eighteen days after operation. Early hydronephrosis was seen. However, the distal ureter could not be identified; at reoperation, it was crammed with debris and its mucosa was found to have sloughed extensively. A conversion was made to ureteroureterostomy. The secondary repair posed a special risk in this case, since the transplant had been performed transperitoneally because of the small size of the recipient. If a urine leak had occurred, it would have drained intraperitoneally.

B. Fifty-three days after transplantation and 35 days after secondary ureteroureterostomy. Note the anastomosis (arrow). Both above and below this site there is slight ureteral dilatation.

homograft was removed. Histologically, there was evidence of acute rejection in the kidney as well as in the pelvis and ureter. The ureteral mucosa had sloughed and caused a mechanical obstruction distally.

Acute Obstruction. Of the four obstructions, two that were complete were caused by extensive slough of the distal ureteral mucosa with consequent plugging of the ureteroneocystostomy anastomosis with debris (Fig. 6). In one, the pelvis of the homograft had a patch of necrosis which had not perforated.

One of the two incomplete obstructions was due to necrosis of the ureteral tip. The other was apparently the result of a preexisting low grade stricture which had not been recognized in the donor pyelogram (Fig. 7A) and which became aggravated when the kidney was moved to its new location (Fig. 7B).

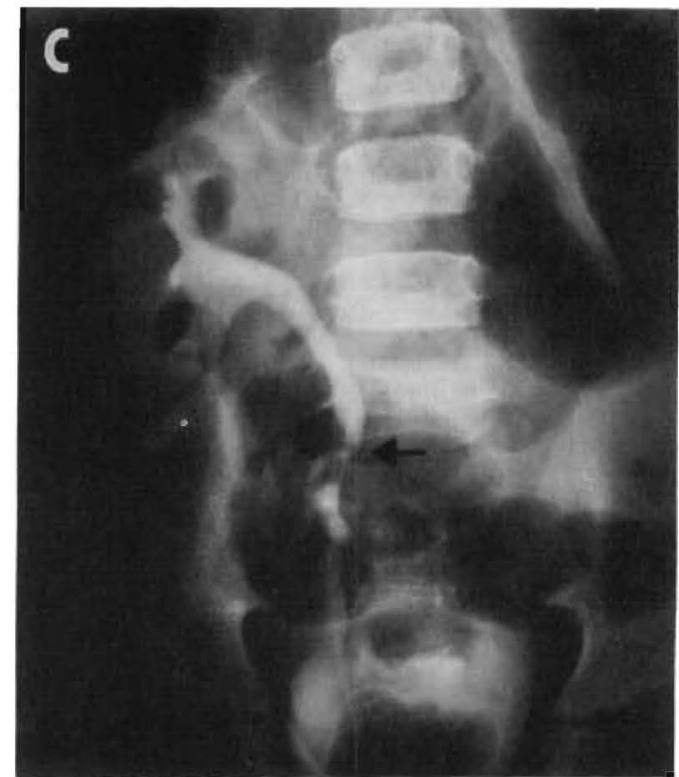

FIG. 6C. One year post-transplantation. The anastomosis (arrow) can just be made out. All three $\mathrm{x}$-rays were performed 10 minutes after dye injection. 

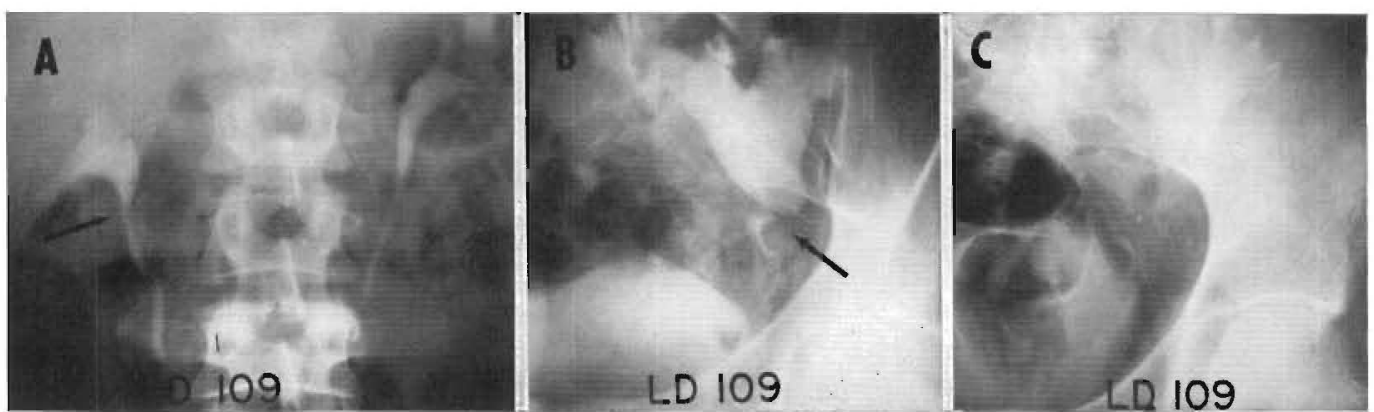

FxG. 7. Hydronephrosis resulting from an undiagnosed ureteropelvic narrowing in the donor kidney. A. An intravenous urogram of the donor before transplantation showing the lesion at the ureteropelvic junction. The significance of the finding was not appreciated. B. The same kidney after transplautation. In the new left pelvic position, the proximal stenosis became more severe. Uperation became urgent because of cleclining renal function. $C$. Nine months after delayed repair. Kidney function was normal and has remained so.

\section{Late Complications (After Six Weeks)}

Twenty-three of the 178 kidneys that had been drained by ureteroneocystostomy could not be followed for longer than 6 weeks either because the patients died or because the transplanted organs had been removed. With the remaining 155 homografts, urologic complications which required reoperation were encountered in seven.

Stricture. In five, late reconstruction was required because of ureteral strictures which were diagnosed from $3 \frac{1}{2}$ months to
$2 \frac{1}{2}$ years after homotransplantation. In four of these, the obstructions were at the ureteroneocystostomy (Fig. 8) and in the other in the proximal ureter (Fig. 9). Minor hydronephrosis has been diagnosed in two other chronically tolerated homografts but repair of the anastomotic strictures has not been considered.

Shelf-like proximal strictures have also been observed in the homograft ureters of three other recipients (Fig. 10). These have caused minimal or no hydronephrosis, and are not listed in the table of complications. The patients have been followed with serial
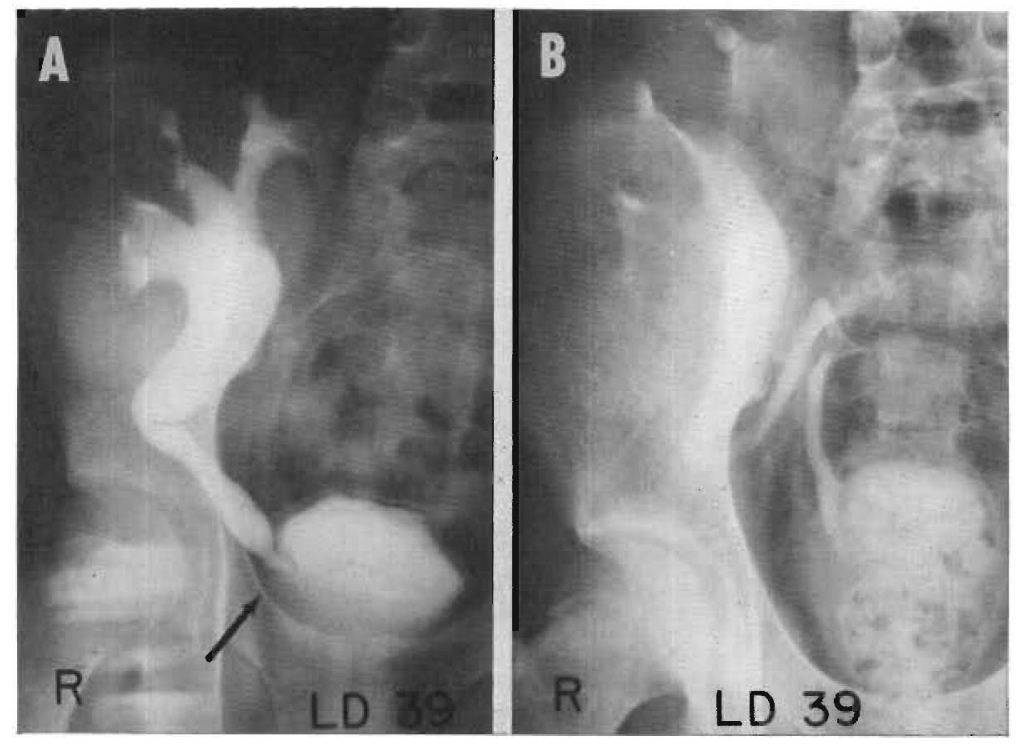

FxG. 8. Partial obstruction at the ureteroneocystostomy stoma. A. IVP 4 months posttransplantation. BUN was $19 \mathrm{mg}$./ $100 \mathrm{ml}$. and CCr. $82 \mathrm{ml}$. per min. B. Two and a half years after conversion to ureteroureterostomy. The patient is now 6 years post-transplantation. 
FiG. 9. A. Obstruction of the proxinal ureter 8 months after homotransplantation in a paticnt who had ureteroneocystostomy. B. After conversion to ureteroureterostomy, the patient's own ureterovesical junction was slightly dilated. Ultimately the kidney was rejected and the patient died 33 months posttransplantation.
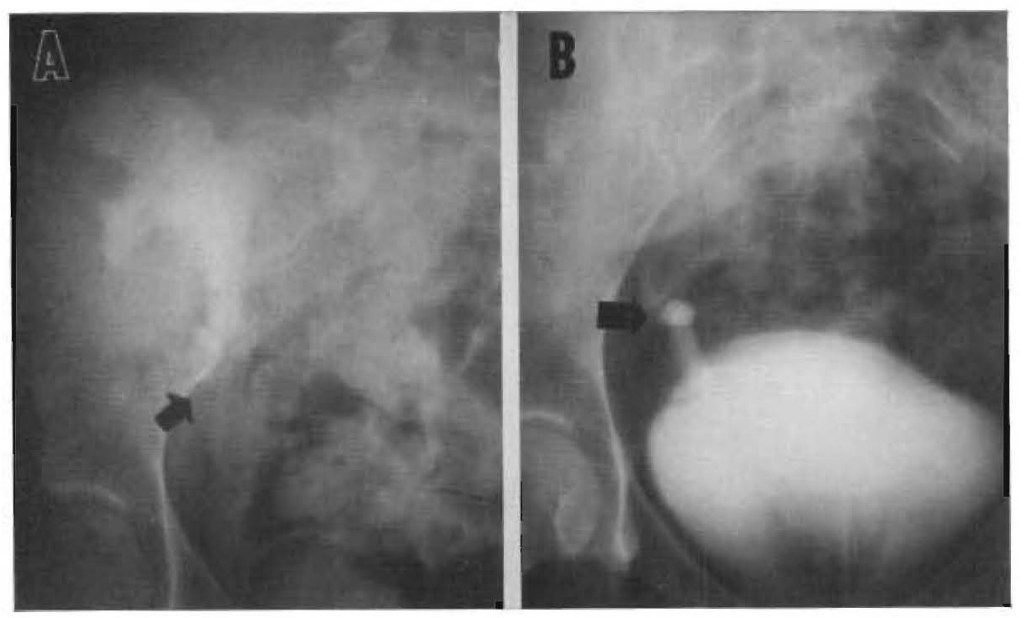

intravenous pyelograms for as long as 6 years, without evidence of progression.

Lymphocele Compression. In three patients, lymphoceles were detected with intravenous pyelography after three, 12 , and 15 months by external compression of the homograft ureter (Fig. 11). The two larger collections were treated surgically (see below); the smaller one is being followed by serial intravenous pyelograms.

Chronic Pyelonephritis. Persistent bacteriuria was documented after eight of the 118 transplantations in which observations were carried out for 1 to $71 / 2$ years after the performance of primary ureteroneocystostomy. However, in three, there had been complications from the original operations necessitating revision of the urinary drainage routes in procedures that tended to be complicated and to require prolonged catheterization. Late deterioration of renal function was observed in one of the eight patients.

Cystotomy Wounds. The bladder counterincisions through which the ureteroneocystostomies were performed were not the cause of either acute or chronic complications in any of the 178 operations. In no case has stone formation been observed either at the site of the bladder closure or at the ureteroneocystostomy.
Outcome of Primary Ureteroureterostomy

There were 55 primary ureteroureterostomies and one ureteropyelostomy. These

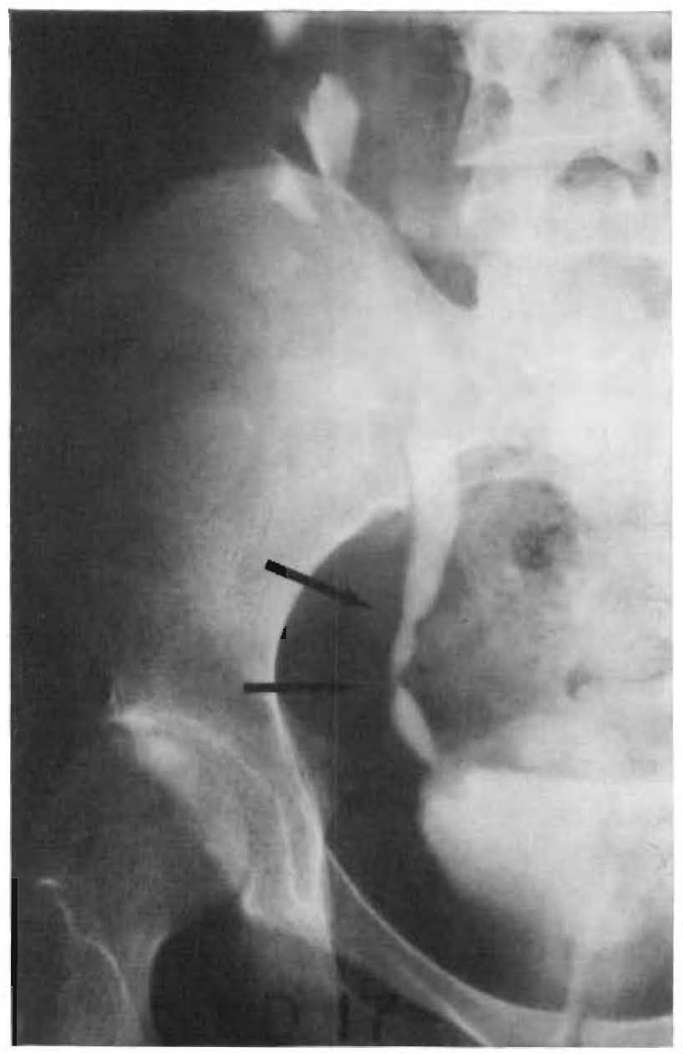

FIG. 10. Shelf-like non-obstructing strictures in a homograft ureter. Correction has not been required in the $6 \frac{1}{4}$ years since transplantation. 

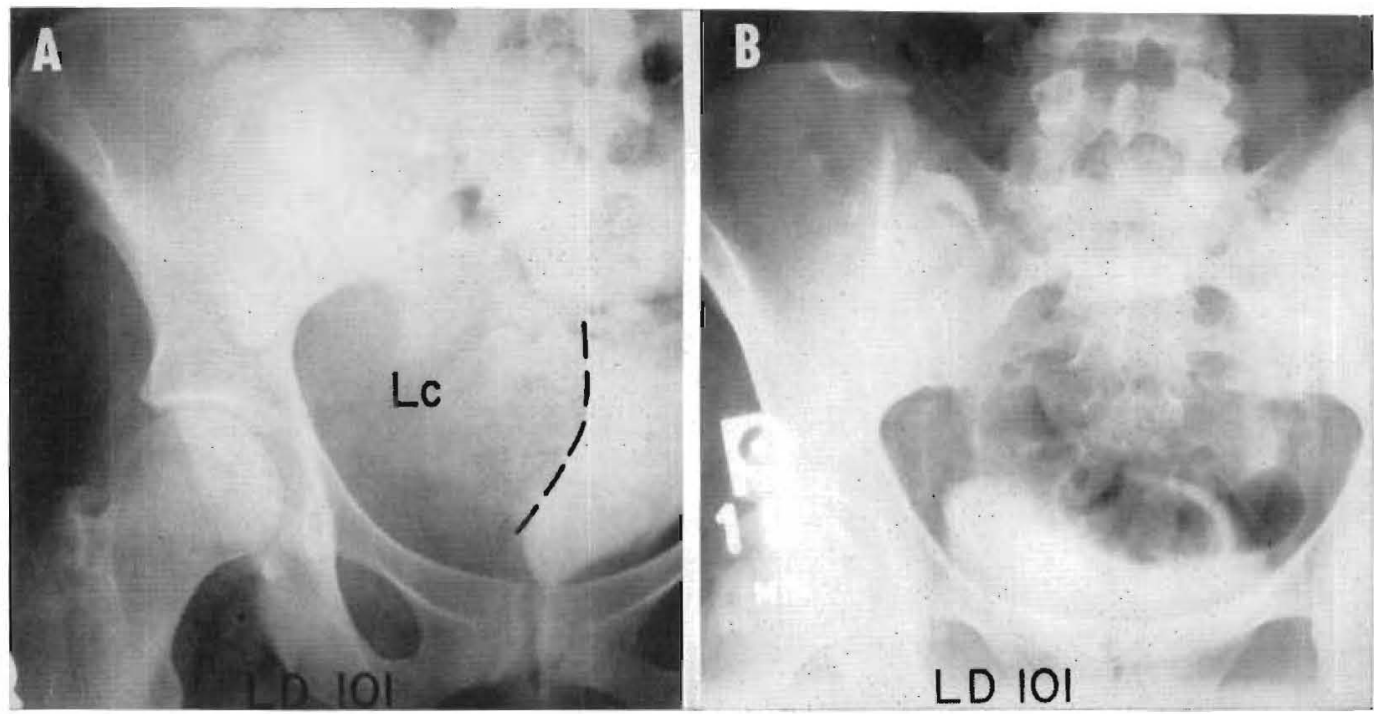

Fig. 11. A. Ureteral obstruction 3 months postoperatively, caused by a large lymphocele (Lc) in the transplant wound. The bladder deformity is evident. B. After drainage of the lymphocele the hydronephrosis was completely relieved. The patient is now $3^{1}, 2$ years postoperative.

will be considered together since the technic of anastomosis was identical (Table 1). Complications necessitating reoperation were encountered after seven transplantations $(12.5 \%)$. When these complications were avoided, the results were gratifying in patients who now have been followed for at least 5 years. In Figure 12 are shown examples of several configurations taken by the reconstructed ureters.

In two cases, it was necessary for technical reasons to perform an anastomosis with diseased distal recipient ureters. The autologous ureter of one recipient was several times the diameter of the companion homograft structure. The cause of the dilatation was later found to be a bladder neck obstruction which was corrected 2 months post-transplantation by transvesical V-Y plasty. The other patient's original diagnosis was chronic pyelonephritis. The right ureter to which anastomosis was performed was about $3 \frac{1}{2}$ times the diameter of the homograft ureter, but no specific cause for the abnormality was ever demonstrated.

There were no unusual postoperative difficulties and both patients still have ex- cellent renal function $4 \% 3$ and $23 / 4$ years, respectively, after transplantation. In both instances there has been a slight reduction in the caliber of the host ureters (Fig. 13). Neither patient has developed chronic pyelonephritis.

\section{Early Complications (First Six Weeks)}

Urinary Fistula. Six (10.9\%) of the 55 primary ureteroureterostomies developed urinary leaks which were diagnosed on postoperative days $1,6,21,25,41$, and 42 . The entire ureter of one homograft had undergone necrosis. The etiology of the fistulas in the other five was not apparent.

Other Complications. There were no examples of hemorrhage or obstruction. In fact, the ureteroureterostomy proved to be free of early complications except for the fistulas mentioned above.

\section{Late Complications (After Six Weeks)}

Calculus Formation. Ten months after operation, one patient was readmitted because of pain at the transplant site. An in- 


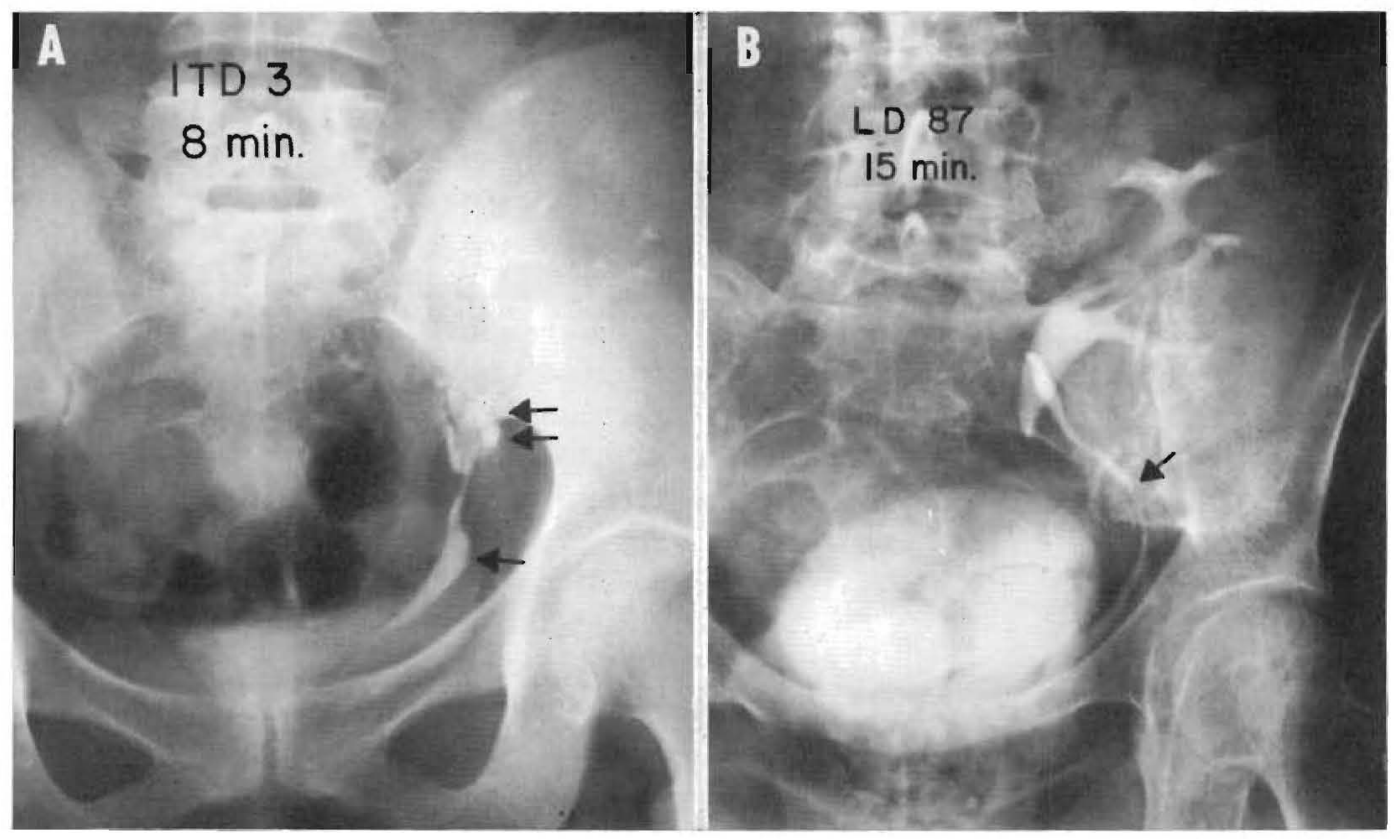

Fig. 12. Late intravenous urograms in patients whose transplants had urinary tract reconstruction by primary ureteroureterostomy. A. Three years posttransplantation. 'l'he donor was an identical twin. The reconstructed ureter makes a complete loop (double arrow). The anistomosis cannot be identified. Note the slight dilatation of the distal recipient ureter (arrow). B. Four years after transplantation from a non-related donor. Since care was taken not to trcise too much host or homograft ureter there was almost always a redundancy of the reconstructed channel. The anastomosis was thought to be at the site indicated by the arrow, but it could not be identified with certainty.

travenous pyelogram showed urinary extravasation at the ureteroureterostomy and dilatation of the homograft ureter (Fig. 14). The ureteral anastomosis was excised and the ureters reanastomosed. At this time a stone was found which had apparently caused obstruction of the anastomosis and which had ultimately eroded through it.

Another patient spontaneously passed a small stone 16 months after homotransplantation. Intravenous pyelograms before and after this time were normal. The source of the stone was never discovered. He is now 4 years postoperative.

Stricture. There has been one example of anastomotic stricture causing minimal hydronephrosis which has not progressed. The patient's renal function remains normal $21 / 2$ years after operation and reintervention is not planned.

Chronic Pyelonephritis. Thirty-seven of the 55 kidneys supported life for 1 to 5

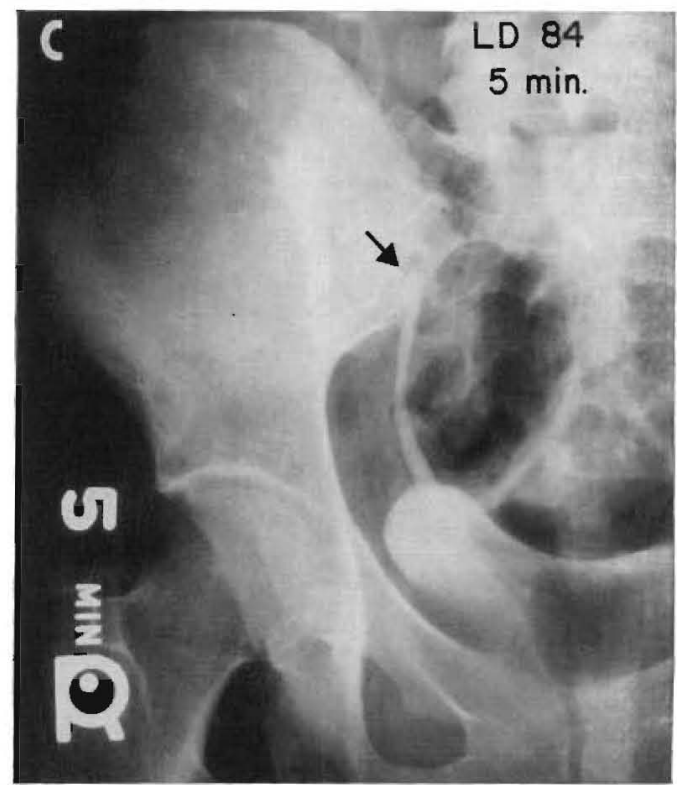

FIG. 12C. Study obtained more than 4 years after transplantation from a younger sister. The general area of anastomosis is marked (arrow), but its exact location could not be seen. 


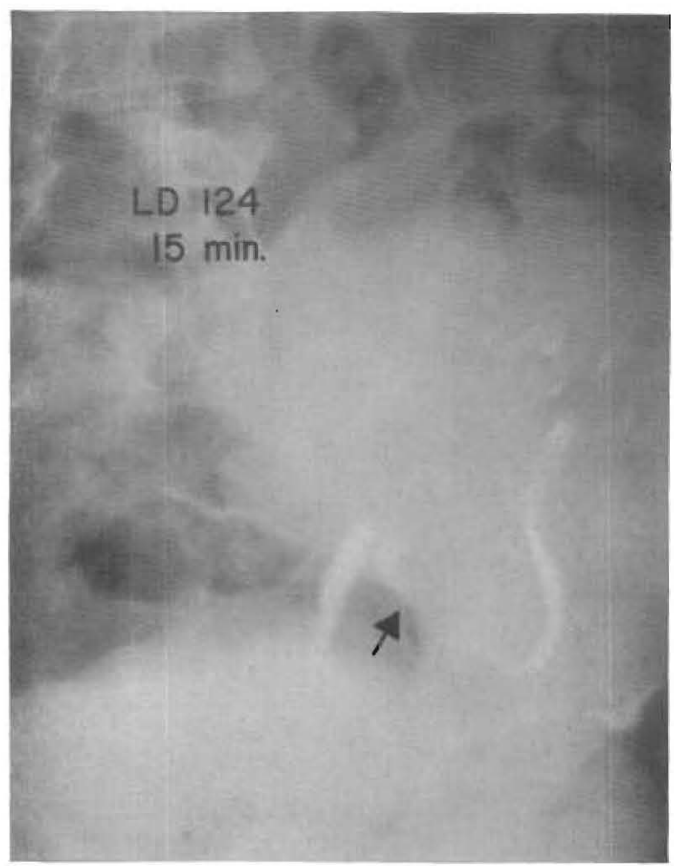

Fig. 13. The appearance of a ureteroureterostomy (arrow) 21/2 years after transplantation. At the time of operation, the homograft ureter was of normal size but the recipient ureter was markedly dilated. The anastomosis was successful. Eventually the host ureter decreased in caliber but never to normal size.

years after transplantation and ureteroureterostomy. In this group, there were only two homograft recipients $(5 \%)$ who had bacteriologic eviclence of chronic pyelonephritis. In the two exceptional cases, renal function has been stable for $2 \frac{1}{2}$ and 4 years, respectively.

\section{Diagnosis of Urologic Complications}

Diagnosis may be difficult since the consequences of urologic complications can be mimicked by rejection. For example, ureteral obstruction, urinary fistula, and rejection can all cause decline in renal function, fever, and wound tenderness and swelling. In approximately $90 \%$ of patients with these changes, the diagnosis ultimately proves to be rejection; a favorable response to intensification of steroid therapy may be one of the best clues that this is the situa- tion. For this reason, diagnostic instrumentation such a cystoscopy is done sparingly, only for compelling indications, and very often only after there has not been a favorable response to an increase in immunosuppression.

One such indication is the suspicion that a postoperative anuria may be due to a complete ureteral obstruction. This is a particularly important possibility if good initial urine excretion was observed. Under these circumstances, a renogram may be valuable in determining whether or not the kidney is viable.1,16, 21,25 However, the chimges in renograms do not differentiate between rejection and obstruction. ${ }^{1,24,25}$ In some cases, an emergency intravenous pyelogram will provide the diagnosis. If not, cystoscopy is the next step. Such a systematic approach to diagnosis will prevent tragic exrors of omission. Complete anuria in the early postoperative period due to poor control of rejection has become ixceedingly uncommon in recent years and consequently another explanation is automatically suspect.

Late partial obstructions are usually detected in the course of routine follow-up with intravenous pyelograms. Anyone with slow deterioration of renal function or a persistent urinary tract infection is a candidate for more extensive urologic tests.

Either early or late after transplantation, care must be taken to be sure that a hydronephrosis is mechanical rather than the result of (or at least coincident with) rejection. The best clue that the latter may be the case is the presence of suddenly increased proteinuria, a finding which is highly indicative of rejection and distinctly atypical of obstruction. In three ureteroneocystostomies generalized dilatation of the extra renal collecting system was demonstrated concomitant with deterioration of renal function 1 week, 6 weeks and 15 months, respectively, after transplantation. There appeared to be an area of narrowing 


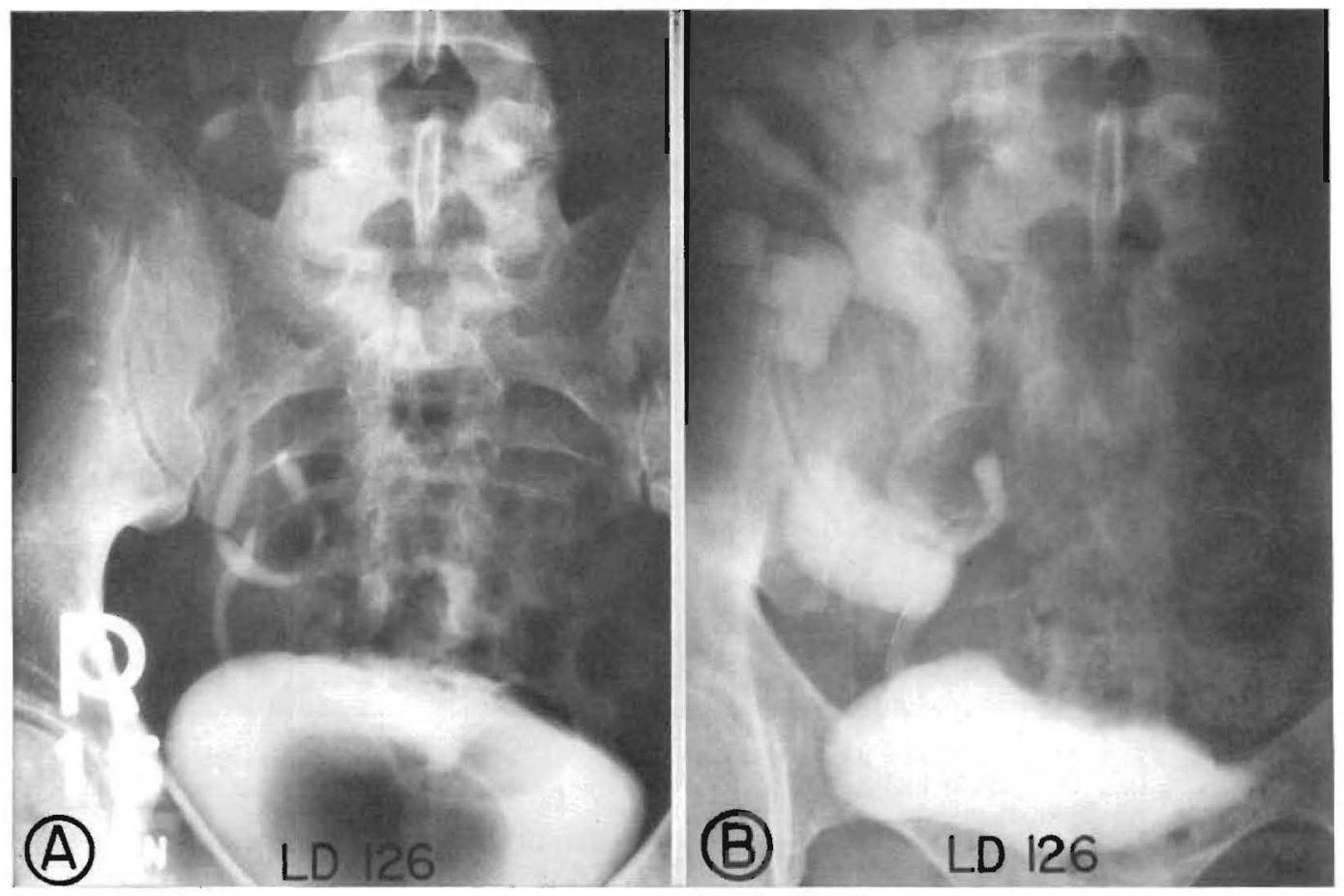

FIG. 14. Intravenous urograms in a patient who developed a late complication of ureteroureterostomy which was caused by a calculus that formed at the anastomosis and caused its perforation. A. Ten weeks postoperative. B. Ten months postoperative. Note the slight hydronephrosis and the area of urinary extravasation.

at the site of the implantation (Fig. 15A). However, the ureteroneocystostomies were shown to be widely patent by cystoscopy and retrograde pyelography. With an increase in steroid dosage, there was prompt improvement in renal function as well as a restoration toward normal of subsequent intravenous pyelograms (Fig. 15B).

Urinary fistulas may also be diagnostic problems. When drains have been used an early urinary leak is usually obvious, but in some cases differentiation between serous drainage and urine may be difficult. If good renal function is present, comparison of the urea and creatinine concentrations in the draining fluid with those of the blood plasma and bladder urine usually provides an unequivocal diagnosis. With poor renal function, however, the concentrations of these constituents are elevated in the blood and usually lower than normal in the urine making the distinction between plasma and urine an unreliable one.

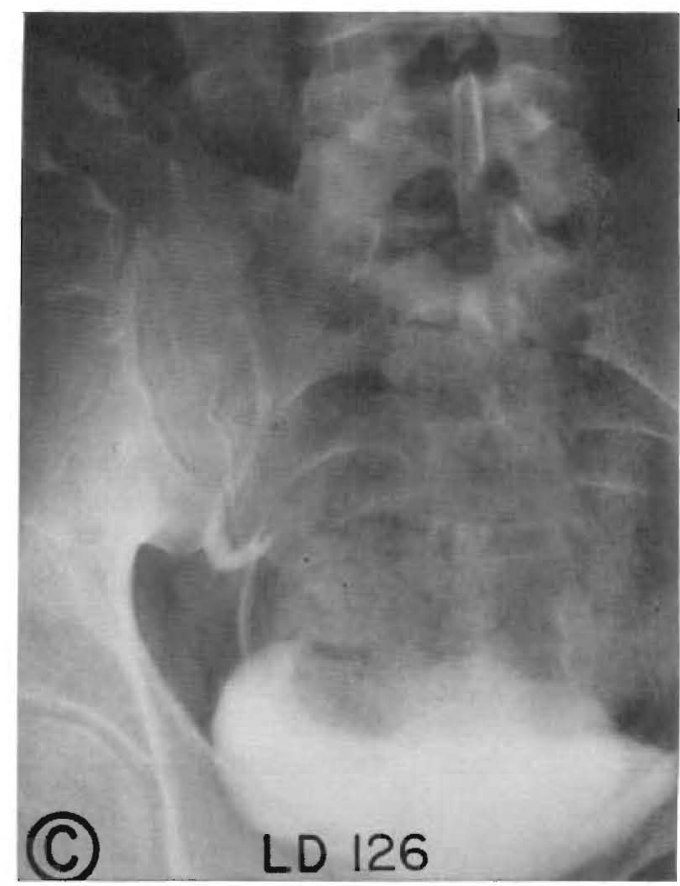

Fig. 14C. Three months after reperformance of ureteroureterostomy. The patient is now $23 / 4$ years posttransplantation. 

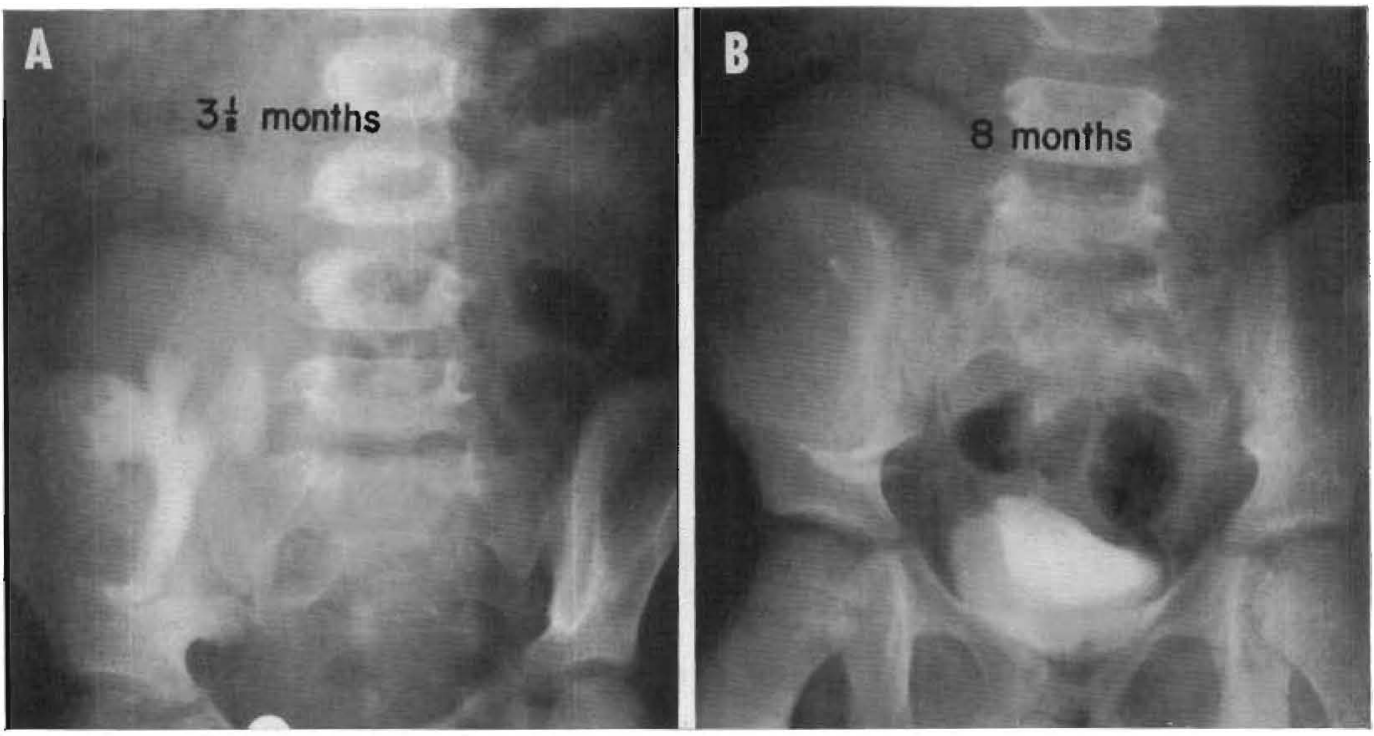

Fic. 15. A. Hydronephrosis which developed $31 / 2$ months after cadaveric transplantation at the same time the patient had a rise in BUN which could have been due to mechanical obstruction. However, there was also marked proteinuria. The daily doses of prednisone were increased. There was prompt resolution of the proteinuria, the azotemia and the hydronephrosis. The urinary tract reconstruction was with ureteroneocystostomy. B. Hydronephrosis is no longer present.

When the urine does not drain to the skin as in patients who do not have drains or in those whose drain tracts have closed, an intravenous and/or retrograde pyelogram may show extravasation.

\section{Outcome after Reoperation for Urologic Complications}

As already mentioned, there was a striking difference (Table 1) in results of reoperation in the first 6 postoperative weeks as compared to the results obtained after this time. All eight of the patients in the latter group recovered and all lived for at least 1 year. Six of these recipients are still alive with continuing function of originally transplanted kidneys after $14,33,44,68$, 69 , and 70 months; the other two died after their homografts failed after 33 and 63 months, respectively.

In contrast (Table 1 ), five of the $15 \mathrm{pa}$ tients whose complications were diagnosed during the first six postoperative weeks suc- cumbed as the direct consequence of urologic difficulties; three more died within the next few months of pneumonitis, granulomatous colitis, and massive liver necrosis. The mortality in the latter recipients was not directly ascribable to urologic complications but the cumulative adverse effects of repeated anesthetics, poor renal function, heavy immunosuppression and protracted invalidism were contributory factors that derived from failure to achieve an initially perfect technical result. Only seven of the 15 patients were alive at the end of a year. One of the seven died of hepatitis after 18 months, the other six are surviving with function of their original kidney transplants after 16,34,39, 43, 50 and 58 months.

Reperformance of Ureteroneocystostomy

Reimplantation of the ureter was carried out twice, once after 6 days for fistula and once after 29 days for obstruction. The fis- 
tula in the first case was controlled but the patient developed a severe wound infection and died 11 weeks posttransplantation despite continued good renal function. In the other patient who was reoperated upon at the end of a month, the homograft ureter had become obstructed by debris from an extensive slough of mucosa. The kidney did not function well after the corrective procedure and the child died a week later.

The technic of secondary ureteroneocystostomy was the same as for primary ureteral implantation. However, the procedures were so difficult and bloody that ureteroneocystostomy has not been used for a secondary repair in more than $5 \frac{1}{2}$ years. Indeed, reliance has been placed on ureteroureterostomy or ureteropyelostomy.

\section{Secondary Ureteroureterostomies}

Ureteroureterostomies were performed at reoperations in 15 patients for the indications listed in Table 1, of which ureteral obstruction or urinary fistula were the most common. At eight of the operations ureteroneocystostomies were taken down and the resulting defects in bladder wall closed before beginning ureter to ureter anastomosis. In the other seven, failed primary ureteroureterostomies were excised, the homograft and host ureters mobilized for some distance, and the anastomoses reperformed.

In converting from ureteroneocystostomy to ureteroureterostomy or ureteropyelostomy there was no difficulty in pulling host ureters into the transplant wounds even though the nephrectomies had been performed previously. Moreover, the defunctionalized recipient ureters were found patent and in good condition even after as long as $2 \frac{1}{2}$ years.

The usual technic of secondary ureteroureterostomy was the same as that described (Fig. 3, 4). However, thickening and telescoping of the layers of the ureteral

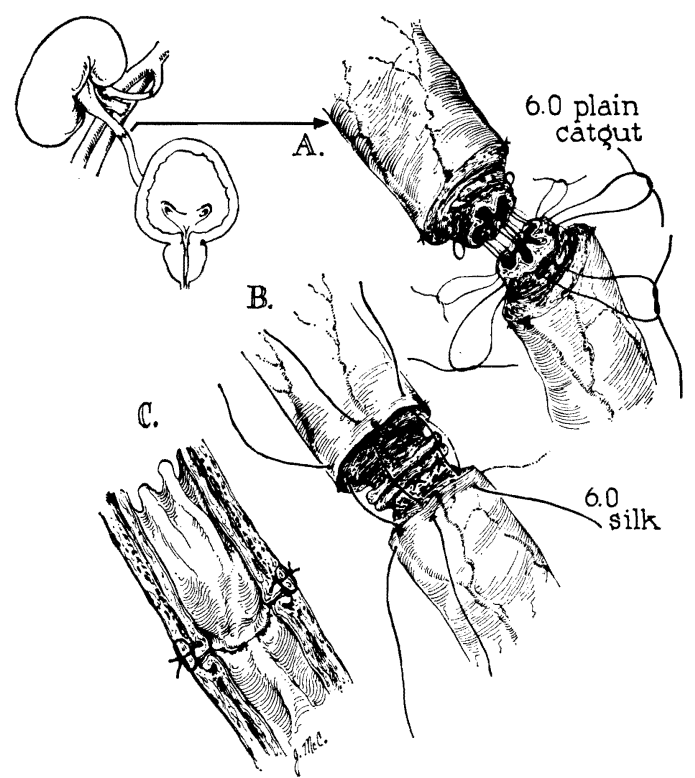

Fig. 16. Two layer technic of anastomosis occasionally used when late ureteroureterostomy was necessary in the presence of edematous tissue.

wall in two cases were so extreme that a two layer anastomosis was employed. An inner mucosal closure was made with horizontal mattress sutures of 6-0 plain catgut (Fig. 16A), over which an external row of interrupted simple 6-0 silk sutures was superimposed (Fig. 16B, C).

For 11 of the 15 kidneys, an anatomically satisfactory drainage system was obtained with a single reoperation (Fig. 17). In two others, two or three reinterventions were required. One patient had a stricture of the initial ureteroneocystostomy. Two days after conversion to ureteroureterostomy, a urinary fistula developed, necessitating reanastomosis. Three weeks later the fistula recurred. At reoperation a small defect in the suture line was identified and closed. Postoperatively, urinary leak continued, necessitating transurethral placement of a ureteral catheter through the anastomosis into the renal pelvis. It was left in place for 2 weeks during which time the fistula healed. Another patient with urinary extravasation was reoperated upon 3 weeks 

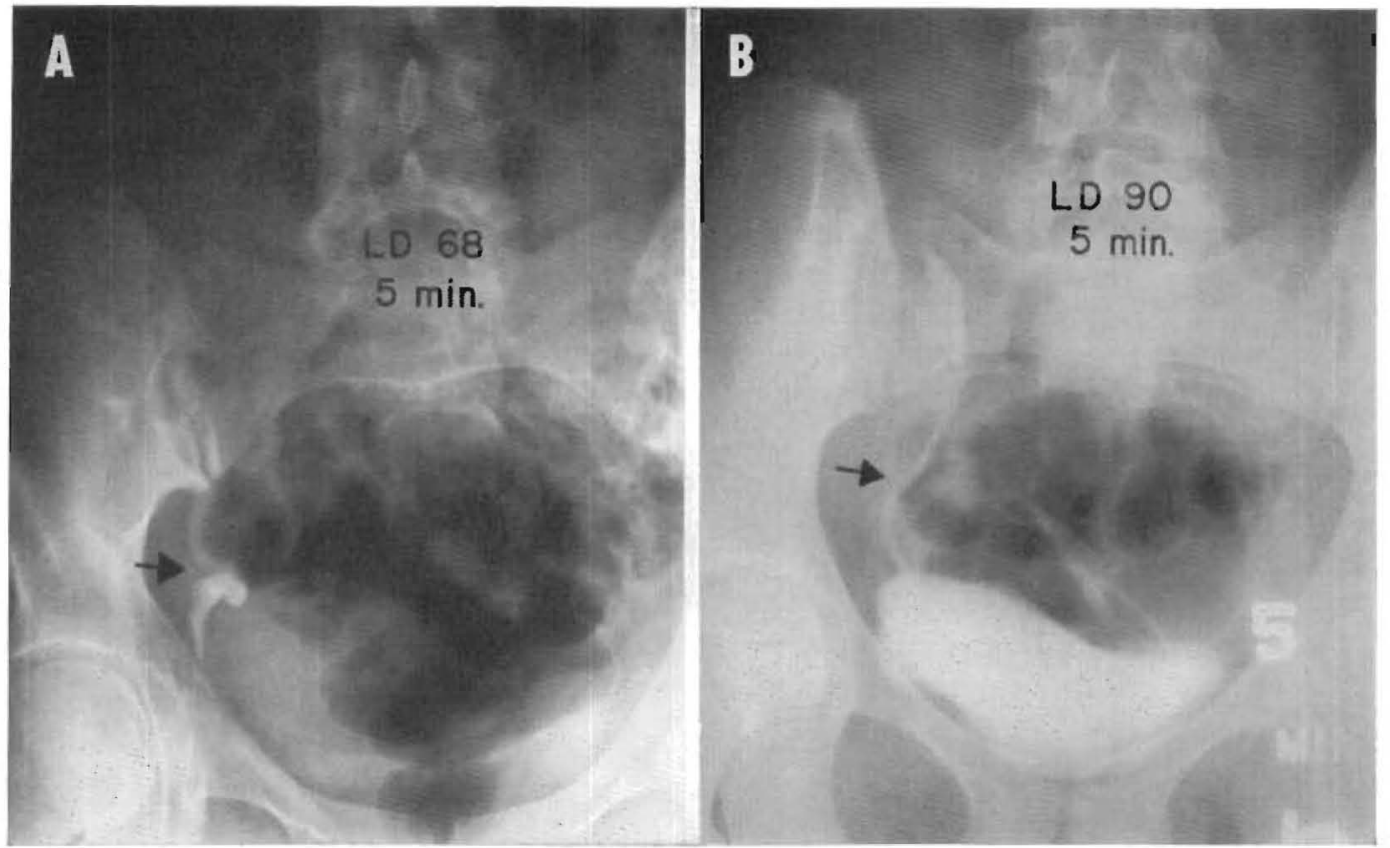

FIG. 17. The late intravenous urograms of two patients who developed early postoperative urinary fistulas which were cured by secondary ureteroureterostomies. A. The initial reconstruction was with ureteroneocystostomy which failed because of necrosis of the distal ureter. The general area of the life saving ureteroureterostomy is indicated (arrow), although its exact location cannot be seen. The homograft continues to function well after 5 years. B. The initial reconstruction was with a ureteroureterostomy. When this leaked after 3 weeks, the anastomosis (arrow) was reperformed. She is now more than 3 years posttranplantation. One year ago she gave birth to a normal baby.

after primary ureteroureterostomy and a tiny defect in the anastomosis closed with a single suture. The fistula promptly recurred and was not controlled until the anastomosis was reperformed after 4 months.

Two urinary fistulas which developed after primary ureteroureterostomy could never be cured. In one case, urine leaked a few hours after transplantation. At reoperation, there was necrosis of most of the homograft ureter. The new anastomosis leaked 7 days later necessitating a third operation. Now, there was insufficient ureter available for reconstruction. The kidney was excised, cooled and transferred to the contralateral (left) iliac fossa. Ureteroureterostomy was employed, but hemorrhage from the anastomosis caused obstruction of the pelvis and ureter with clot. The anastomosis was redone one day later.
Within a week the urine leak recurred. It could not be controlled despite three additional attempts at reconstruction. Eleven weeks posttransplantation, a communication developed between the fistula tract and the renal venous anastomosis with a consequent major hemorrhage. The homograft was excised but the patient died of wound infection and septicemia 4 days later.

The other patient whose fistula could not be closed developed an anastomotic leak I week postoperatively. Reanastomosis was performed 5 days later, but the leak resumed after 2 weeks. During the next 4 months, three more similar attempts at repair were unsuccessful. The patient died 8 months after transplantation of wound infection and septicemia. 


\section{Secondary Ureteropyelostomy}

All three secondary ureteropyelostomies were for the relief of obstructions following primary ureteroneocystostomies. The technic in one was essentially the same as with ureteroureterostomy since the anastomosis was end-to-end to the neck of the pelvis. This patient still has good renal function $23 / 4$ years posttransplantation.

In the other two patients, this simple approach was not possible since in both the pelvis was directed inferiorly at such an angle that its termination could not be conveniently attached to the recipient ureter. Consequently, the dependent part of the pelvis was excised by the technic shown in Figure 18D. The resulting defect was partially closed with an inner layer of continuous chromic catgut and an external layer of interrupted silk. The ureteral anastomosis was then made to the medially oriented residual orifice. In one case, the ipsilateral recipient ureter was used (Fig. 7C). Recovery was prompt and the patient has perfect renal function 3 years later.

The convalescence of the other patient who had a modified ureteropyelostomy was complicated. In this case, it was planned to reimplant the homograft ureter into the bladder but unfortunately its distal portion became necrotic (Fig. 18A, B). Since the recipient ureter on that side had been previously excised, it was necessary to bring the other ureter across the midline and attach it to the pelvis (Fig. 18C). A urinary fistula developed which was intermittently present for the next 3 months. Healing did not occur until the dependent portion of the pelvis, which served as a pus pocket, was excised at a later operation (Fig. 18D). Ultimately five major operative procedures and nine endoscopies were required before the fistula closed. During the ensuing $4 \frac{1}{2}$ years, the homograft was the site of chronic pyelonephritis. On several occasions, monilial fungus balls caused

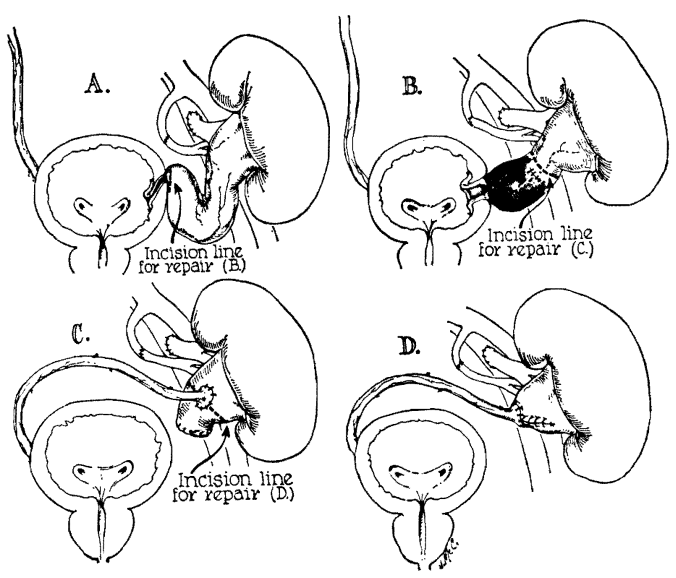

Fig, 18. Treatment of a late partial obstruction at the ureteroneocystostomy stoma. A, B. Initial attempt at ureteral reimplantation at $51 \frac{1}{2}$ months concomitant with a Heineke-Mikulicz ureteropyelostomy. The latter was done because of kinking and tortuosity at the ureteropelvic junction. The distal ureter sloughed. C. Anastomosis of the contralateral ureter to the anterior surface of the pelvis. A urinary fistula developed. D. Final reconstruction. The dependent pelvis was excised since it was a focus of infection.

acute obstruction of the anastomosis (Fig. 19). These disappeared after transureteral instillation of amphotericin B. The homograft finally failed and was removed more than 5 years after transplantation.

\section{Drainage of Lymphoceles}

The two lymphoceles treated surgically were drained by reopening a portion of the transplant incision. Within a few weeks the lymph leak ceased. There was prompt regression of the hydronephrosis caused by external compression of the ureter (Fig. 11). The two patients are now 14 and 42 months posttransplantation, respectively.

\section{Discussion}

The mention by several authors of urologic complications following renal transplantation $2,3,5,9,11,13,14,17,29-32$ indicates that such problems are by no means unusual and are attended by high morbidity and mortality, particularly with urinary fis- 

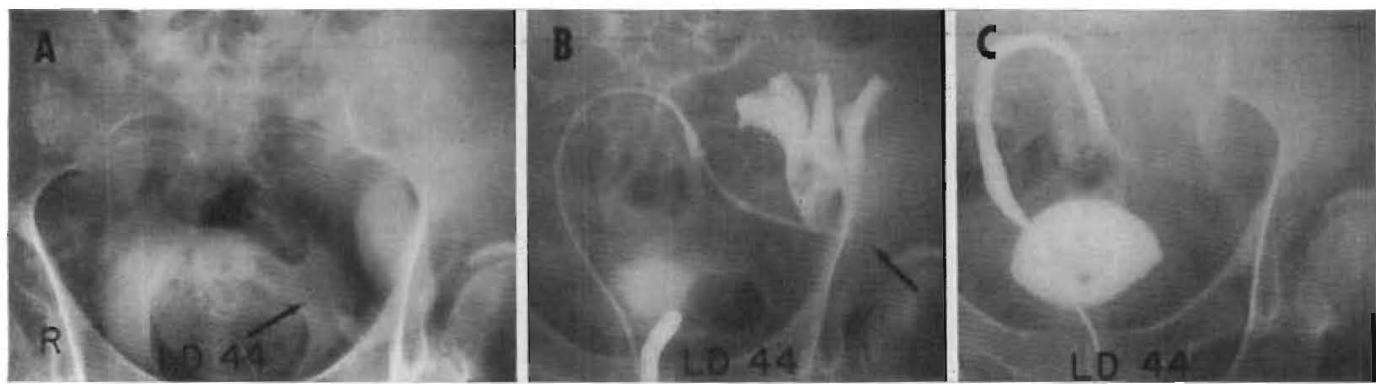

Fri. 19. Studies in a patient who developed obstruction of a ureteroneocystostomy. A. Intravenous urogram 5 months after transplantation. The site of the stricture at the ureteroneocystostomy is indicated by an arrow. The obstruction was relieved during the ensuing 3 months by the series of operations depicted in Figure 18. B, C. Retrograde pyelogram 6 months after the secondary repair by ureteropyelostomy. The endoscopy was performed because of sudden anuria, which was apparently caused by obstruction from fungus accumulations in the pelvis (note arrow in B). The fungus balls were washed out with amphotericin B. The kidney supported life for more than 5 years after transplantation before it finally failed.

tulas. However, there have been only a few detailed reports on this important subject. $12,15,18,21,25$

The results in the present study and in a number of others cited above have proved that establishment of urinary drainage from renal homografts can be accomplished with a high success rate, that long-term patency of the econstructed channels can be expected and that late morbidity from pyelonephritis or chronic obstruction is relatively uncommon. Nevertheless, the imperfections of the technics used are illustrated by the facts that five of our patients died as a direct result of urologic complications and that similar problems contributed to the death of three more.

Since life threatening complications were observed with approximately equal frequency after ureteroneocystostomy and ureteroureterostomy a categoric recommendation of one method in preference to the other may not be warranted on statistical grounds. Nevertheless, it is our opinion that ureteroneocystostomy should usually be the first choice. It requires less technical finesse for its performance, a consideration in institutions such as ours where most of these procedures are currently being carried out by fellows and house officers. In our experi- ence, the operation has had a low incidence of the dangerous complication of urinary fistula. Finally, the procedure ensures preservation of a long segment of homograft ureter for later anastomosis to the patient's retained ureter should that be necessary either early or late after transplantation.

The incidence of serious late ureteroneocystostomy stricture formation was $4.2 \%$ in 118 cases in which a follow-up of one to $7 \frac{1}{2}$ years became available. The stricture was in the proximal ureter in one, but it was at the anastomotic site in the other four. It is probable that a systematic technical error was introduced during the 10 week interval when the latter four recipients were operated upon. They were treated between November 13, 1963, and January 25,1964 . Prior to this time 40 transplantations had been performed with ureteroneocystostomy taking care to vigorously dilate the muscular portion of the tunnel through which the homograft ureter was brought. Twenty-one of these early patients lived for at least 1 year and 16 are alive after six to $71 / 2$ years; the other five died after $13,24,31,33$, and 52 months. There were no late strictures at the implantation site. In the next 12 cases adequate tunnel dilatation was apparently not performed. Ten 
of these recipients lived for at least 1 year and four developed partial obstructions at the anastomotic sites. In the subsequent $5 \% 3$ years since the presumed error has been avoided, this complication has not been seen.

With the alternative procedure of primary ureteroureterostomy the main disadvantage was a $10.9 \%$ incidence of early urinary fistula. Although this complication was eventually controlled in four of six cases, secondary repair of the fistulas was more difficult since considerable lengths of both the homograft and recipient ureters had already been sacrificed at the first operation. In the two patients who died with uncured fistulas the inability to mobilize adequate segments for reanastomosis was a major factor in the outcome. The same disadvantage probably also applies to the alternative procedure of ureteropyelostomy used by Leadbetter et al. ${ }^{11}$ and Palmer et al. ${ }^{18}$ Both authors reported urinary fistulas and obstructions in their patients.

In patients who did not develop urinary fistulas the advantages of primary ureteroureterostomy were impressive. Macroscopic hematuria postoperatively was either completely absent or minimal. Only two $(5.4 \%)$ of 37 patients followed for longer than a year had late bacteriuria, an incidence that was slightly lower than the $6.8 \%$ obtained with ureteroneocystostomy. Moreover, there was only one serious late complication, that being caused by the formation of a calculus.

Although it may be that ureteroneocystostomy as the primary procedure is preferable for the reasons cited, skill with the alternative methods of uretero-ureteral or uretero-pelvic anastomoses is desirable if not essential in the field of transplantation. If the homograft ureter is too short at the time of the initial operation the only feasible solution may be with ureteroureterostomy or ureteropyelostomy. Moreover, the latter procedures have been of the utmost importance in treating complications after unsuccessful first operations. In our series, the majority of complications of ureteroneocystostomy were eventually dealt with by attaching the ureter or pelvis of the homograft to the recipient's own ureter rather than by ureteral reimplantation.

The treatment of urologic complications after renal homotransplantation is not yet standardized, particularly with respect to indications for surgical reintervention some months or years later. For example, the operations for the few patients with ureterovesical strictures were elective since there had not yet been deterioration in renal function. In the Medical College of Virginia series, four such cases were described in which reconstruction was not done. ${ }^{21}$ An argument for the wisdom of the latter conservative approach was the fact that the hydronephrosis regressed in one instance and had remained stable for as long as 2 years in the other three. Nevertheless, the demonstration in the present report that late corrective procedures were possible without a mortality would make us willing to consider reoperation in similar asymptomatic patients in the future.

Although the wisdom of correcting late asymptomatic hydronephrosis in transplant patients can be debated, there may be no reasonable alternative to prompt re-operation when urologic complications appear in the early postoperative period. In our experience, several homografts were irreparably damaged because of delay in correcting acute obstructions or (in one instance) ureteral hemorrhage due to venous infarction. Similarly, the best time to correct an acute urinary fistula is probably soon after the diagnosis is made, after a short period of observation (usually only a few days) to be sure that spontaneous closure will not occur.

With a urinary leak, the urgency of establishment of a water-tight urinary system has no parallel in standard urologic practice. In a patient who has the normal ca- 
pacity to heal and resist infection, most urinary fistulas would be expected eventually to close spontaneously. The same is not true in the recipient of a renal homograft who must be treated with potent immunosuppressive agents of which the one with the greatest morbidity has proved to be prednisone. ${ }^{6,26}$

Under these circumstances, immunosuppressive drugs upon which continued urine excretion depends, dispose the patient to infection in the transplant wound. The magnitude of the risk can be appreciated by the high incidence of bacteriuria, ranging from 40 to $80 \%$, which has been reported in the early post-transplantation period in large series of recipients. ${ }^{7,21,22,25}$ At the same time there is retardation of the healing process by which the threat posed by a urinary fistula might be eliminated. Because of these special considerations, our policy has been to attempt to surgically close the fistulas before the supervention of wound sepsis. In several cases in which the secondary repair also failed it was possible to make one or more additional attempts within a short time.

The extra hazard to wound healing imposed by immunosuppressive therapy is generally conceded and the need for such treatment undoubtedly contributes to the incidence and gravity of ureteral complications. However, it could also be logically speculated that failure to administer adequate quantities of the immune suppressing agents could make the hazard greater. The homograft ureter is subject to the same general injury from rejection as the renal parenchyma as has been well documented by Porter, ${ }^{19,}{ }^{20}$ by Haber and Putong ${ }^{4}$ and by Robertshaw et al. ${ }^{23}$ These authors described round cell infiltration, acute or subacute vascular lesions, muscle necrosis, and mucosal slough. Thus, there is a variable added handicap of performing a visceral anastomosis with tissue that is under immunologic attack.
Although "isolated ureteral rejection" has been the subject of speculation, ${ }^{21}$ there has been no support for this concept in our material, ${ }^{19,}{ }^{20}$ or in other large series. ${ }^{23}$ In kidney homografts of the University of Colorado series, the histopathologic findings of early or late rejection in the ureter have usually been consistent with the histologic signs of rejection in its attached kidney. ${ }^{19,} 20$ Parenthetically it might be added that at the time rejection was diagnosed in three cases there was evidence on intravenous pyelography of functional disturbances including dilatation in the homograft ureters. With increases of steroid dosage, renal function was restored toward normal and there was a reduction in ureteral dilatation.

This does not mean that rejection may not cause late ureteral obstruction. A hallmark of the repair of immunologic injury is fibrosis. This may occur either within the kidney or in its pelvis or ureter. In one previously reported case in our series ${ }^{25,27}$ a cicatricial stricture developed many months after operation at a considerable distance from the ureteroneocystostomy site. There have been other examples, described in the present communication, in which shelf-like indentations have been demonstrated with intravenous pyelography in similar locations. In some patients, these defects have remained stable for many years. Such lesions do not represent selective ureteric rejection. Instead, they are probably stigmata of healed rejection in which the scarring occurred in a particularly strategic and easily visualizable location.

\section{Summary}

The technics used to re-establish urinary tract drainage of 234 kidneys which were transplanted to 216 recipients are described. The operations were performed from one to $7 \frac{1}{2}$ years ago. Original reconstructions were with ureteroneocystostomy (178), ureteroureterostomy (55) and ureteropyelos- 
tomy (one). Serious urologic complications occurred at approximately a $10 \%$ incidence after both primary ureteroneocystostomy and primary ureteroureterostomy.

High mortality attended complications which developed during the first 6 postoperative weeks and which required reoperation; the indications for reintervention included urinary fistula (nine), urinary obstruction (four), and hemorrhage (two). If ureteroneocystostomy had been the original procedure, this was usually changed to a ureteroureterostomy or ureteropyelostomy. Defective ureteroureterostomies were excised and the anastomoses reperformed, or else a conversion was made to ureteropyelostomy. Of these 15 patients, eight died within the first year; five of the deaths were directly attributable to the urologic complications.

In contrast, there was no mortality in secondarily correcting urologic complications that developed several months to $2 \frac{1}{2}$ years posttransplantation. These included five late strictures, two obstructions from external compression by lymphoceles, and one ureteral calculus that eroded through a ureteroureteral anastomosis. The reconstructive procedures for the six intrinsic ureteral lesions were ureteroureterostomy (five) and ureteropyelostomy (one). The lymphoceles were drained.

On the basis of our experience, ureteroneocystostomy is recommended in most cases of transplantation in preference to ureteroureterostomy or ureteropyelostomy as the method of urinary tract reconstruction to be used initially. Although it does not have a materially lower complication rate, it does not involve the unnecessary sacrifice of either host or homograft ureter, thereby keeping all avenues open for secondary repair should that become necessary. Skill with all three types of reconstruction is necessary in the field of renal transplantation if homograft and patient loss is to be kept at a minimum.

\section{References}

1. Anderson, E. E. and Wilson, R. E.: Radioisotope Renography and Radioscintillation Scanning in the Diagnosis of Homograft Rejection. Surg. Gynec. Obstet., 122:1273, 1966.

2. Brown, R. B.: Urological Complications of Renal Homotransplantation. Brit. J. Urol. (Abstract) , 40:492, 1968.

3. Goodwin, W. E., Kaufman, J. J., Mims, M. M., Turner, R. D., Glassock, R., Goldman, R. and Maxwell, M. M.: Human Renal Transplantation. I. Clinical Experiences with Six Cases of Renal IHomotransplantation. J. Urol., 89:13, 1963.

4. Haber, M. H. and Putong, P. B.: Ureteral Vascular Rejection in Human Renal Transplants. JAMA, 192:417, 1965.

5. Hamburger, J., Crosnier, J., Dormont, J., Reveillaud, R. J., Hors, J. H. and Alsina, J.: Homotransplantation renale humaine. Resultats personnels chez 52 malades. III. Complications extra-renales-Conclusions d'ensemble. Presse. Med., 73:2911, 1965.

6. Hill, R. B., Jr., Dahrling, B. E., Starzl, T. E. and Rifkind, D.: Death after Transplantation: An Analysis of 60 Cases. Amer. J. Med., 42:327, 1967.

7. Hinman, F., Jr., Schmaelzle, J. F. and Belzer, F. O.: Urinary Tract Infection and Renal Homotransplantation: II. Post-transplantation Bacterial Invasion. J. Urol., 101:673, 1969.

8. Hume, D. M., Magee, J. J.., Kauffman, H. M. Rittenburg, M. S. and Prout, G. R.: Renal Homotransplantation in Man in Modified Recipients. Ann. Surg., 158:608, 1963.

9. Kelly, W. D., Lillehei, R. C., Aust, J. B., Varco, R. L., Leonard, A. S., Griffin, W. O., Markland, C., Herdman, R. C., Vernier, R. L., Michael, A. F. and Levitt, J.: Kidney Transplantation: Experiences at the University of Minnesota Hospitals. Surgery, 62:704, 1967.

10. Kuss, R., Teinturier, J. and Millienz, P.: Quelques essais de greffes du rein chez l'homme. Mem. Acad. Chir., 77:755, 1951.

11. Leadbetter, G. W., Monaco, A. P. and Russell P. S.: A Technique for Reconstruction of the Urinary Tract in Renal Transplantation. Surg. Gynec. Obstet., 123:839, 1966.

12. MacKinnon, X. J., Oliver, J. A., Morehouse, D. D. and Taguchi, Y.: Cadaver Renal Transplantation: Emphasis on Urological Aspects. J. Urol., 99:486, 1968.

13. MacLean, L. D., MacKinnon, K. G., Inglis, F. G. and Dossetor, J. B.: When Should Renal Allografts Be Removed? Arch. Surg., 99:269, 1969.

14. Martin, D. C., Goodwin, W. E., Kaufman, J. J., Mims, M. M., Goldman, R., Rubini, M. and Gonick, H.: Kidney Transplants: 92 Cases. Results, Lessons Learned, Future Prospects. J. Urol., 100:227, 1968.

15. Martin, D. C., Mims, M. M., Kaufman, J. J. and Goodwin, W. E.: The Ureter in Renal Transplantation. J. Urol., 101:680, 1969. 
16. Mobley, J. E. and Schlegel, J. U.: Radiohippuran Accumulation in the Transplanted Kidney as a Signal of Rejection. Surgery, 58:815, 1965.

17. Murray, J. E. and Harrison, J. H.: Management of 50 Cases with Kidney Transplants Including 18 Pairs of Twins. Amer. J. Surg., 105:205, 1963 .

18. Palmer, J. M., Kountz, S. L., Swenson, R. S., Lucas, Z. J. and Cohn, R.: Urinary Tract Morbidity in Renal Transplantation. Arch. Surg., 98:352, 1969.

19. Porter, K. A.: Pathological Changes in Transplanted Kidneys. In Starzl, T. E.: Experience in Renal Transplantation. Philadelphia, W. B. Saunders, Co., p. 299, 1964.

20. Porter, K. A., Marchioro, T. L. and Starzl, T. E.: Pathological Changes in 37 Human Renal Homotransplants Treated with Immunosuppressive Drugs. Brit. J. Urol., 37: $250,1965$.

21. Prout, G. R., Jr., Hume, D. M., Lee, H. M. and Williams, G. M.: Some Urological Aspects of 93 Consecutive Renal Homotransplants in Modified Recipients. J. Urol., 97: 409, 1967.

22. Rifkind, D., Starzl, T. E., Marchioro, T. L. and Waddell, W. R.: Infectious Diseases Associated with Renal Homotransplantation. I. Incidence, Types and Predisposing Factors. JAMA, 189:397, 1964

23. Robertshaw, G. E., Madge, G. E. and Kauffman, H. M., Jr.: Ureteral Pathology in Treated and Untreated Renal Homografts. Surg. Forum, 17:236, 1966.

24. Sharpe, J. A. R., King, R. E., Hume, D. M., Lee, H. M. and Kauffman, H. M.: Sequential Response of the Iodine-131 Hippuran
Renogram in Renal Homotransplantation. J. Nucl. Med., 7:556, 1966.

25. Starzl, T, E.: Experience in Renal Transplantation. Philadelphia, W. B. Saunders Co., 1964.

26. Starzl, T. E., Marchioro, T. L. and Iwasaki, Y.: Attributes of Clinically-used Immunosuppressive Drugs; the Possible Future Value of Antilymphoid Sera. Fed. Proc. (Symposia issue) (\#3), 26:944, 1967.

27. Starzl, T. E., Marchioro, T. L., Porter, K. A. Moore, C. A., Rifkind, D. and Waddell W. R. Renal Homotransplantations and Complications. Ann. Int. Med., 61:470, 1964.

28. Starzl, T. E., Porter, K. A., Iwasaki, Y., Marchioro, T. L. and Kashiwagi, N.: The Use of Heterologous Antilymphocyte Globulin in Human Renal Homotransplantation. In Antilymphocytic Serum (Ed. Wolstenholme, G. E. W. and O'Connor, M.). London, J. and A. Churchill Ltd., p. 4, 1967.

29. Straffon, R. A., Kiser, W. S., Stewart, B. H., Hewitt, C. B., Gifford, R. W., Jr. and Nakomoto, S.: Four Years Clinical Experience with 138 Kidney Transplants. J. Urol., 99: $479,1968$.

30. Straffon, R. A., Stewart, B. H., Kiser, W. S., Hewitt, C. B., Nakomoto, S. and Kolff, W. J.: The Use of 94 Cadaveric Kidneys for Transplantation-Clinical Experience. Brit. J. Urol., 38:640, 1С66.

31. Walsh, A.: Some Practical Problems in Kidney Transplantation. Transplantation Proceedings, 1 (No. 1):178, 1969.

32. Woodruff, M. F. A., Nolan, B., Robson, J. S. and MacDonald, M. K.: Renal Transplantation in Man. Experience in 35 Cases. Lancet, $1: 6,1969$. 